\title{
Chronic Suppurative Otitis Media Atticoantral- Type Undergone Canal Wall Down Mastoidectomy in a Peripheral Government Hospital of Nepal
}

Dhundi Raj Paudel ${ }^{1}$

'Department of ENT, Bharatpur Hospital, Bharatpur, Chitwan, Nepal.

Introduction: Chronic suppurative otitis media is a severe type of chronic ear infection which is quite common in all geographical situations of Nepal. The mainstay of treatment of this disease is surgery, preferably of canal down method. The objective of the study was to identify the common presentation(s) and the clinical and operative finding(s) in patients with chronic suppurative otitis media attico-antral type and evaluation of efficacy of canal-wall down mastoidectomy in the achievement of dry ear and change in hearing in a setting of a peripheral hospital of Nepal in terms of subjectivity.

Methods: Per-operative evaluation of mastoid cavities in terms of types of pathologies and postoperative assessment of ears in terms of achieving a dryness and change in hearing ability was carried out in the ENT Department, Bharatpur Hospital, Chitwan, Nepal. Study was done from January 2005 to December 2010. Patients with chronic suppurative otitis media atticoantral- type were evaluated preoperatively in terms of gross pathologies. Postoperatively, patients were subjectively evaluated twice in six months in reference to persistent ear discharge and change in hearing ability.

Results: By six months of surgery, $75 \%$ of the patients had no discharge. Fifty two patients did not experience any change in hearing ability. Only 16\% experienced betterment in hearing while 19\% had diminution in hearing.

Conclusions: Canal wall down mastoidectomies are very effective in controlling otorrhoea and complications related to chronic suppurative otitis media attico-antral type.

Keywords: Chronic suppurative otitis media attico-antral (CSOM-AA) type; CWD masoidectomy; CWU mastoidectomy; ear cavity.

INTRODUCTION

Chronic suppurative otitis media-atticoantral (CSOM-AA) is a common disease of Nepal. It involves predominantly the attic and antral region of the middle ear cleft. ${ }^{1,2}$ It is usually associated with serious complications and considered as a dangerous disease. ${ }^{3}$

Correspondence: Dr. Dhundi Raj Paudel, Senior Consultant, ENT surgeon, Bharatpur Hospital, Chitwan, Nepal. Email: dhundi_paudel@ yahoo.com, Phone: +977-9855055866. 
Paudel. Assessment of Per-operative Findings and Post-operative Evaluation of Patients With Chronic Suppurative...

The disease is often associated with a bone eroding process i.e. by cholesteatoma, granulations or osteitis. ${ }^{4}$ Otorrhoea is usually scanty andfoulsmelling. ${ }^{5}$ Canal wall down(CWD) mastoidectomy is usually recommended and has comparatively high success rate than canal wall up(CWU) procedures. CWU method requires regular follow-up which is not possible in the peripheral parts of the country where easy access is not possible.

Even though CWD mastoidectomy has the higher success rate then CWU mastoidectomy in achieving dry ear cavity, still it has some failure rate. The success rate depends on the technical expertise and availability of physical facilities. The main purpose of this study is to assess the success rate of CWD masoidectomy in achieving dry ear in a peripheral governmental hospital of Nepal.

\section{METHODS}

The records from mastoid forms as designed by Institute of Medicine, Kathmandu, Nepal of 73 patients, underwent CWD mastoidectomy in Bharatpur Hospital, Chitwan, Nepal during the period of January 2005-December 2010 were reviewed and evaluated.

The patients undergone CWD mastoidectomy who could be followed up at least twice in 6 months were included in the study. Endaural approach was done in 53 most and in the remaining 20 cases, the approach was post auricular.

\section{RESULTS}

\begin{tabular}{|llll|}
\hline \multicolumn{4}{|l|}{ Table 1. Age and sex wise distribution. } \\
\hline Age group & Male & Female & Total \\
Under 10 & 2 & 4 & 6 \\
$10-20$ & 16 & 11 & 27 \\
$20-30$ & 12 & 9 & 21 \\
Above 30 & 9 & 8 & 19 \\
\hline
\end{tabular}

Preoperative findings: Foul smelling discharge was present in 44 and it was absent in 29 patients. Sixteen patients had various complications. Seven had mastoid abscess and six had fistula. Two were complicated with intracranial abscesses while one had extradural abscess.

Peroperative findings: Cholesteatoma was found in 16 patients. Nine patients had only the mucosal type disease. Granulation tissue was present in 11 patients. In the remaining 37 patients both the cholesteatoma and granulation were seen. All ossicles including head of stapes were necrosed partially or completely in 23 patients. Only incus was necrosed in 21 cases. All ossicles were intact in 7 cases. Ossicular status could not be assessed in 22 patients due to various reasons.Twenty six cases were undergone type 3 tympanoplasty. Grafting on stapes area was done in 32 cases. No grafting was placed in 15 cases.

Complication: Various complications were encountered with surgery. Seven patients had post-operative facial palsies. It was temporary in five and those patients could be recovered of it. In the remaining two the facial palsy was persistent.

One female patient of 29 years died suddenly on ninth post-operative day. Cause of death couldn't be ascertained.

\section{Post-operative follow up}

\section{Discharge}

One month after surgery $42(57 \%)$ patients had no discharge while 31 (43\%) patients had discharge. Three to six months after surgery 18 (25\%) patients had minimal to significant discharge while 55 (75\%) patients developed dry ear (cavity).

Post-operative changes in hearing ability as experienced and felt subjectively by the patients in the last follow up. There was no change in 38 (52\%); 12 (16\%) experienced betterment in hearing ability. Among the patient 14 (19\%) experienced diminution and 9 (13\%) patients could not define.

\section{DISCUSSION}

To start the mastoid surgeries in a peripheral governmental Hospital in Nepal is a very difficult task owing to administrative hassles, financial constraints and lack of awareness.

Previous results and experiences have clearly made it evident that canal wall down procedures are very effective in controlling the disease especially to eradicate cholesteatoma, decrease granulations formation and controls otorrhoea to a greater extent.

In a retrospective study, Vartiainen et al. ${ }^{6}$ examined results of canal wall down mastoidectomy for acquired cholesteatoma of 136 patients who had undergone canal wall down mastoidectomy. The result showed that $98 \%$ of the operated ears were dry, $1 \%$ moist, and one ear $(0.7 \%)$ was discharging. These results show mastoidectomy to be an effective treatment from chronically draining ears and don't validate results where this study could achieve only $75 \%$ ears dry 3 -6 months after surgery. The main reason behind this is leaving behind the pathologies around the facial nerve 
Paudel. Assessment of Per-operative Findings and Post-operative Evaluation of Patients With Chronic Suppurative...

and stapes area. At the beginning panicky and fear of damaging the facial nerve used to make hesitant to be aggressive in removing the diseases.

Paparella et al. ${ }^{7}$ reviewed long-term results of 375 primary mastoidectomy operations for chronic otitis media and chronic mastoiditis. Cholesteatoma was present in 125 patients and granulation tissue in 250 patients. But in our study only 16 out of 73 had cholesteatoma. About $50 \%$ of patients had mixed pathologies in this study. One third of his patients underwent canal wall up and two-thirds canal wall down mastoidectomies. He recommended that onestage canal wall down mastoidectomy is better than multiple planned procedures to reduce unnecessary hospitalization and expenses. This aspect is important in our society where patients are lost to follow-up. That's why all of patients in this study underwent canal wall down mastoidectomies.

Hirsch et al. ${ }^{8}$ retrospectively reviewed 164 cases with cholesteatoma surgically managed from 1980 through 1986. In 81 cases modified radical mastoidectomies, and in 36 radical mastoidectomies were performed compared with 47 canal wall up mastoidectomies, concluded that single-stage management of cholesteatoma with modified radical mastoidectomy (canal wall-down) required fewer revisions for recidivistic cholesteatoma. In our series all the 73 patients had undergone modified radical mastoidectomy with no grafting in 15 cases attributed to complications e.g. mastoid abscess and compulsion of leaving pathologies. Otherwise, classical radical mastoidectomy was not performed in any cases.

Roden et al. $^{9}$ in a 12 years retrospective review of mastoid surgery for cholesteatoma included 97 mastoid procedures. He concluded that while canal-wall-down mastoidectomy provides a lower residual disease rate with equal hearing outcome, the role of intact wall mastoidectomy remains a viable choice in certain clinical situations. Review of literature has shown that nowadays most authors prefer canal wall up procedure i.e. combined approach mastoidectomy due to function preservation. But in our setup canal wall down mastoidectomy is preferred because of the reason that the patient followup is poor and we lack optimum level of expertise on combined approach tympanoplasty.

There is upto a $40 \%$ chance of recurrence or persistence of the cholesteatoma in case of canal wall up procedure. ${ }^{10}$

In 1024 mastoid surgery cases performed by Nillsen et al, ${ }^{11} 17$ had iatrogenic facial nerve palsy with seven complete with no recovery. We had two cases with no recovery. The patients who had no indrawing of face at all immediately after surgery recovered from facial palsy. The main cause for complete palsy was trauma to dehiscent facial nerve with drill or microinstrument at the area with excessive granulation tissues.

In Nepal 299 cases underwent CWD mastoidectomy were evaluated by Thapa et al. ${ }^{12}$ in Tribhuvan University Teaching Hospital Kathmandu Nepal. Among those patient $96.39 \%$ underwent CWD mastoidectomy had dry ear which is excellent result. This achievement could be attributed to long experience in surgery and development of expertise in the field of otology in TUTH. They could save facial nerve in 298 cases to be paralyzed completely. We have not compared different types of canal wall down procedures, as this was not the objective of our study. Follow up is poor. Therefore main aim was to make the ear dry and safe rather thancatering for hearing ability.

The author doesn't hesitate to admit that there were some limitations of this study. Exact and similar previous articles were searched but couldn't be found. The author was solely concerned to post-operative achievement in terms of patient's complains, experience and feelings in a peripheral governmental hospital of the developing country like Nepal where we are bound to work with minimal facilities and constraints.

When this study was carried out, a lot of difficulties were faced. Even the patients had to be reminded of, by telephone to come for follow-up. Post-op followup is quite difficult in our setting due to various causes e.g. transportation, travelling difficulties, financial constraints and reluctancy of patients to comply with treating doctor's advice.

\section{CONCLUSIONS}

Such subjective evaluations should be carried out following CWD mastoid surgeries. Regular training on mastoid surgeries should be conducted for ENT surgeons' team to achieve optimum result.

Mastoid surgery should be expanded to peripheral hospital of Nepal. Peripheral hospital should be enriched with facilities and trained manpower in order to provide better ear care services, prevent complications and deafness. Public awareness programs should also be launched.

\section{REFERENCES}


1. Gantz BJ, Wilkinson EP, Hansen MR. Canal wall reconstruction tympanomastoidectomy with mastoid obliteration. Laryngoscope. 2005;115:1734-40.

2. BerrettiniS, Ravecca F, de Vito A, Forli F, ValoriS, Franceschini SS. Modified Bondy radical mastoidectomy, long-term personal experience. J Laryngol Otol. 2004;118:333-7.

3. Garap JP, Dubey SP. Canal-down mastoidectomy: experience in 81 cases. OtolNeurotol. 2001;22:451-6.

4. Akhtar MR, Ahmed T, Ahmed B. Complication of cholesteatoma. J Coll Physician SurgPak. 2002;12:324.

5. McElveen JT Jr, Chung AT. Reversible canal wall down mastoidectomy for acquired cholesteatomas: preliminary results.Laryngoscope. 2003 Jun;113(6):1027-33.

6. Vartiainen E. Ten-year results of canal wall down mastoidectomy for acquired cholesteatoma. AurisNasus Larynx. 2001;27(3):227-9.

7. Paparella MM, Kim CS. Mastoidectomy update Laryngoscope. 1977 Dec;87(12):1977-88.
8. Hirsch BE1, Kamerer DB, Doshi S. Single-stage management of cholesteatoma. Otolaryngol Head Neck Surg. 1992 Apr;106(4):351-4.

9. Roden D1, Honrubia VF, Wiet R. Outcome of residual cholesteatoma and hearing in mastoid surgery. J Otolaryngol. 1996 Jun;25(3):178-81.

10. Brown OE, Meyerhoff WL. Complications and Sequelae of Chronic Suppurative Otitis Media. Ann OtolRhinolLaryngol. 1988;97:131(Suppl):38-40.

11. Nilssen EL, Wormald PJ. Facial nerve palsy in mastoid surgery. J Laryngol Otol. 1997 Feb;111(2):113-6.

12. Thapa N, Shrivastav R. Complications of canal-wall down(CWD) mastoidectomy. JNMA. 2003;42:15-8. 